\title{
As ideias e os ideais que definem uma vida: Simone de Beauvoir e Carmen da Silva*
}

Carmen Barroso**

\section{Resumo}

Uma relação teórica entre os princípios existencialistas em $O$ Segundo Sexo, escrito em 1949 por Simone de Beauvoir, e a experiência política de Carmen da Silva. Duas vivências de constituição feminista em cenários ético-políticos bastante distintos entre si.

Palavras-chave: Simone de Beauvoir, Carmen da Silva, Direitos Reprodutivos, Políticas de Gênero e Avanço do Autoritarismo.

* Recebido em 22 de maio de 2019, aceito em 21 de agosto de 2019.

** Co-Chair of the Independent Accountability Panel appointed by the UN. cbarroso2406@gmail.com / http://orcid.org/0000-0002-9452-7086 
The Ideas and Ideals that Define a Life: Simone de Beauvoir and Carmen da Silva

\begin{abstract}
This article examines the theoretical relationship between the existential principles in The Second Sex, written in 1949 by Simone de Beauvoir, and the political experience of Carmen da Silva. They are two experiences in the constitution of feminism in quite distinct ethical-political situations.
\end{abstract}

Keywords: Simone de Beauvoir, Carmen da Silva, Reproductive Rights, Gender policies, authoritarian advance. 
Das minhas múltiplas identidades, há uma que é central: a de feminista. Encontrei as ideias de Simone e de Carmen somente em 1963 e elas deram nome aos sentimentos de inconformismo $e$ rebeldia que eu nutria desde muito cedo, quando aos dez anos de idade declarei à família e amigos que jamais iria me casar, o que me parecia a única forma de escapar ao destino de eterna menoridade que eu via nas mulheres-esposas que me cercavam. A adesão ao celibato não durou muito, pois fiquei feliz de abandoná-la muito cedo, aos 19 anos, quando encontrei o homem que prometia "dar-me toda a liberdade" - que eu, obviamente tive de retificar esclarecendo que a liberdade era minha, e ele fazia muito bem em não a querer cercear.

A questão da autonomia é central n'O Segundo Sexo (Beauvoir, 1949). A coluna A Arte de ser Mulher que Carmen começou a publicar em 1963 na Revista Claudia, com o primeiro artigo sugestivamente intitulado $A$ protagonista, também batia nesta tecla, muito embora somente oito anos depois do início da publicação ela tenha usado "a palavra bicho-papão: feminismo". A mágica que a leitura de Simone e Carmen conseguiu operar na minha cabeça foi a extensão de um problema individual para um diagnóstico coletivo, a compreensão de que a solução envolve uma transformação sistêmica e a metamorfose de uma inquietação pessoal em uma urgência política. Pessoalmente, eu até que tive muita sorte, especialmente na escolha do homem por quem me apaixonei, mas também na relativa escassez de encontros diretos com a discriminação no mundo do trabalho, onde minha escolha profissional de uma área em que mulheres predominavam ofereceu uma certa proteção contra desigualdades mais óbvias. Foram Simone e Carmen, e muitas outras que li mais tarde, que me ofereceram um mapa detalhado das múltiplas ramificações - algumas sutis outras nem tanto - do patriarcado.

Tanto Simone como Carmen tiveram enorme influência tanto pelas ideias radicalmente inovadoras que apresentaram, quanto pelo fato de que viveram feministamente. Se a mensagem central era a de que "não se nasce mulher, torna-se mulher", ambas - de formas muito distintas - fizeram escolhas pessoais que 
demonstravam a possibilidade de modos de vida que escapavam aos padrões tradicionais. Simone, em particular, publicou muitas reflexões sobre sua vida, suas escolhas profissionais e suas relações pessoais. Carmen, que se declarava influenciada por Simone e ironizava ser a "Beauvoir dos pobres", também publicou uma deliciosa autobiografia (Silva, 1984). Não creio que a intenção de nenhuma das duas tenha sido apresentar-se como um exemplo a ser seguido. Em ambos os casos, parecem mais escritoras interessadas em compreender sua própria existência como um caminho de construção de uma identidade plural, profundamente comprometida e engajada com as lutas sociais e políticas de sua época, especialmente com a luta feminista. ${ }^{1}$ Embora elas não se apresentassem como modelos a serem imitados, para nós - suas leitoras - a curiosidade que temos sobre a vida das pessoas que admiramos certamente contribuiu para tirar o feminismo do planeta das utopias e trazê-lo para o terreno das ideias que apontam que um outro mundo é possível, e demonstram esta possibilidade com a narração de uma vida dedicada à sua aplicação na pratica cotidiana.

Companheira de Sartre, pode-se dizer que Simone inicialmente viveu um pouco à sua sombra, porque o mundo intelectual francês reconhecia mais facilmente o brilho de uma inteligência num corpo masculino. Gradativamente alcançou o reconhecimento de seus próprios méritos, e hoje há quem considere que seu legado tenha sido maior que o dele. ${ }^{2}$ Não se trata de fazer comparações, mas a verdade é que ela desde o início rompeu com os padrões tradicionais, afirmando com seus atos e suas escolhas pessoais e profissionais, o direito inalienável

\footnotetext{
1 Carmen generosamente aceitou ser parte do Conselho Editorial do Mulherio, jornal feminista que publicamos na Fundação Carlos Chagas no início dos anos 80, e ainda participava de marchas feministas até um mês antes de sua morte, fantasiada de "rainha do lar", o estereótipo que combateu durante toda a sua vida.

2 Jean Louis Servan Scrieber, entrevistando-a em 1975 pela primeira vez para a televisão francesa, chegou mesmo a levantar a hipótese de que seu livro $O$ Segundo Sexo tenha tido maior influência que O Capital.
} 
de toda mulher de controlar sua própria vida. E o fez de uma forma plenamente consciente. Nos múltiplos relatos e análises que publicou sobre sua experiência, tanto na forma de memórias como de romances autobiográficos, esmiuçou em profundidade tanto os prazeres como a complexidade dos desafios inevitáveis quando alguém decide lançar-se na aventura da invenção de si mesma.

Carmen tinha formação de psicanalista, mas ficou mais conhecida por seu trabalho na literatura e no jornalismo, usando ambos como instrumento para mudar a mentalidade predominante no país onde o marido ainda era definido pela lei como a "cabeça do casal", com autoridade para tomar todas as decisões mais importantes, $e$ a porcentagem de mulheres que exerciam trabalho remunerado era ainda bem pequena. As memórias e os romances autobiográficos de Carmen revelam que ela também viveu suas ideias na prática: deixou a vida confortável de filha de médico de prestígio no Rio Grande do Sul e declarou sua independência indo viver longe da família no Uruguai $e$ na Argentina, um ato ousado que contrariava os costumes $e$ as expectativas vigentes na época, como eu própria pude verificar muitos anos depois quando encontrei a surpresa e a censura velada de amigos e parentes ao comunicar que viria morar nos Estados Unidos.

Este amálgama de ideias e de vivências deu grande credibilidade tanto a Simone como a Carmen, mas de maneiras distintas. Para nós, que estávamos formando nossa identidade feminista nos anos sessenta no Brasil, Simone pertencia ao panteão dos grandes pensadores, uma verdadeira maittraisse a penser, colocada numa posição tão alta, que poderia ser considerada de outro planeta. Eu, particularmente, encontrava uma certa dissonância cognitiva entre a descrição arguta de séculos de cultura patriarcal apresentada tão bem n'O Segundo Sexo e o homem sensível e comprometido com a igualdade de gênero com quem eu estava começando a aventura de compartir cotidiano e sonhos. Abracei as ideias de Simone, mas não via como aplicá-las na minha vida. Somente muito mais tarde cheguei 
a imitar seus passos, quando no discurso de agradecimento pelo prêmio de população que me foi concedido pelas Nações Unidas, aproveitei a oportunidade de ser ouvida pelos diplomatas, muitos dos quais representavam países bastante retrógrados que se opunham aos direitos reprodutivos, e os defendi tornando público o aborto que havia tido quando vivia sob a ditadura e tinha sonhos de resistência que eram incompatíveis com uma gravidez (Barroso, 2016). Carmen, por outro lado, parecia bem mais próxima. Voltando ao Brasil no começo dos anos sessenta, escolheu viver no Rio - aquele paraíso tropical que ela compartilhava com Leila Diniz e outros símbolos da libertação feminina. São Paulo daquela época tinha um certo complexo de inferioridade, mas a distância não era tão grande quanto a da Rive Gauche em Paris. Enquanto Simone trazia a utopia, Carmen nos falava diretamente das possibilidades concretas de exercício da autonomia nas circunstâncias que encontrávamos, sem ignorar os obstáculos existentes por toda parte. ${ }^{3}$

Também havia uma diferença muito grande entre os estilos de linguagem que cada uma adotou. Enquanto Simone escrevia predominantemente para um público mais sofisticado e se atinha a um discurso filosófico, Carmen optou pela linguagem jornalística atraente para o amplo público feminino ansioso por novas ideias, o que garantiu o enorme sucesso da Revista Claudia por mais de duas décadas, quando Carmen recebia até 500 cartas por semana - uma espécie de consultório sentimental em resposta a seus

3 Carmen faz uma auto-crítica bem humorada de sua atitude inicial de minimizar os obstáculos que se interpunham à emancipação de suas leitoras: "Cheguei mesmo a escrever, em Atlântida e El Hogar, alguns artigos dedicados às mulheres, incitando-as a sair da casca, lutar, realizar-se. Esses trabalhos destinavam-se as "outras": eu supunha que as havia, pacatas, mergulhadas na imanência $e$ no marasmo por vontade própria, perdendo as oportunidades $e$ esquivando os desafios da existência por mera falta de fibra e disposição. Sobre elas eu despejava toneladas de saber e suficiência: quanto a mim, era uma iluminada vivendo entre iluminadas. Cabotinismo, teu nome é Carmen da Silva!" (Silva, 1984:95). 
artigos questionadores e provocativos. Sua coluna só terminou em 1985 com a sua morte.

\section{E agora?}

Creio que tanto Simone como Carmen ficariam surpresas com a multiplicação dos frutos das sementes que plantaram, e a permanência $e$ a amplitude do interesse que continuam a despertar. Só para citar um exemplo importante, veja-se a influência de Simone na obra da filósofa americana Judith Butler. ${ }^{4}$ E elas definitivamente continuam a ter impacto muito além dos círculos acadêmicos ou feministas. Em duas viagens que fiz recentemente, uma para Genebra e outra para Washington, encontrei, por acaso, novos livros sobre Simone, o mais inesperado sendo uma obra para crianças na série Little people, big dreams, que meu neto de 9 anos leu com grande interesse (Vegara; Roussey, 2018).

Relendo O Segundo Sexo nos dias de hoje, podemos continuar a admirar a extraordinária erudição e compreender como a influência de seus livros se deveu também ao papel de destaque que Simone tinha na intelectualidade francesa, no momento de muita fermentação $e$ abertura a novas ideias que caracterizou o pós-guerra. Com o conhecimento do que se passou desde a publicação dessa obra que causou tanto impacto, podemos apreciar tanto a perspicácia da análise de certos aspectos, como o excessivo pessimismo ou ingênuo otimismo em relação a outros.

\footnotetext{
4 A pensadora, que foi duramente atacada quando foi ao Brasil em fins de 2017, inspirou-se em Simone desde o início de sua carreira e, como Simone, também tem combinado a produção de teoria com sua aplicação na prática. Em constante diálogo e apoio a movimentos sociais progressistas, ela também parece cultivar uma atitude de respeito e generosidade em suas relações cotidianas, como tive o privilégio de constatar quando a convidei para um drink em "desagravo às ofensas recebidas no Brasil" e ela gentilmente aceitou o convite desta ilustre desconhecida, e presenteou com incentivos, sugestões e apoio, o jovem pesquisador que levei a tiracolo.
} 
Sua relevância para $\mathrm{o}$ debate atual, não obstante transformações imensas no período que nos separa de sua publicação há tantas décadas, se deve ao fato de que algumas das questões básicas continuam não resolvidas ou mostrando progresso apenas parcial. O papel da mulher na reprodução da espécie e os obstáculos que ainda se interpõem à maternidade livre, especialmente o acesso à contracepção e ao aborto, formaram um dos temas centrais de sua análise. Continuava sendo uma questão chave quando iniciei minha carreira nos anos 70 e continuou candente quando, décadas mais tarde, me aposentei, mas não pude me desligar da militância que continua tão necessária.

\section{A maternidade livre: uma questão central ontem $e$ hoje}

O grande desafio do momento atual é que o corpo das mulheres constitui um objeto chave para as novas demagogias nacionalistas de corte reacionário que estão se espalhando nos últimos anos. Quando o presidente do Brasil utiliza sua mais alta tribuna - a do discurso de posse - para atacar aquilo que denomina "ideologia de gênero", não o faz por acaso. Observadores menos atentos podem ter se surpreendido que esse tema seja salientado por um chefe de Estado cuja agenda deveria priorizar politicas sociais e econômicas que atacassem de frente a terrível estagnação econômica na qual o país se afunda cada vez mais. Mas a elevação da chamada ideologia de gênero à categoria de ameaça à estabilidade do país tem sua lógica, ainda que perpassada por interpretações tresloucadas. ${ }^{5} \mathrm{O}$ medo ancestral do poder da sexualidade e a insegurança gerada pelas novas normas de comportamento entre os gêneros criam um terreno fértil para a manipulação de eleitores muito receptivos à invenção de um bode

5 Tendler (2017) já havia levantado a ideia de que a criação do fantasma de uma ideologia de gênero supostamente criadora de um caos sexual tivesse sido construída como arma de defesa da Igreja Católica, ansiosa por desviar a atenção dos abusos sexuais cometidos por seus clérigos, e que não cessam de vir à tona nos últimos anos. 
expiatório para os complexos problemas que enfrentam numa sociedade cada vez mais desigual na distribuição de recursos tanto financeiros quanto intelectuais. ${ }^{6} \mathrm{O}$ feminismo de Simone e de Carmen continuam atualíssimos.

É, no mínimo, paradoxal que a crescente hostilidade à igualdade de gênero se deva, pelo menos parcialmente, ao extraordinário sucesso da ideia no mundo todo. Saboreio esse sucesso imensamente: para mim que, na juventude, achava que conhecia pessoalmente todas as feministas do Brasil - tão poucas éramos - continua a ser uma surpresa agradável cada vez que me vejo cercada de feministas por toda parte, unidas apesar da incrível diversidade de perspectivas e de prioridades. Para citar apenas um exemplo, na conferência mundial de Women Deliver de 2016, quase 6000 pessoas, vindas de mais de 160 países, unânime $e$ orgulhosamente se colocaram de pé ao serem perguntadas se eram feministas. Isto numa conferência que, apenas 9 anos antes, havia atraído menos de 2000 pessoas vindas de apenas 40 países e havia cuidadosamente evitado assuntos mais controvertidos como o aborto.

Não foi somente no campo das ideias que o feminismo operou uma revolução, talvez a mais significativa da nossa era. Também na prática cotidiana de mulheres, em um número cada vez maior de países, houve progresso significativo embora ainda estejamos muito longe da igualdade de direitos. $\mathrm{O}$ avanço alcançado pelo movimento global pelos direitos reprodutivos foi enorme nas décadas desde a publicação d'O Segundo Sexo em 1949. Porém, determinantes culturais, sociais e econômicos, bem como restrições legais ainda se interpõem aos direitos das mulheres de terem os filhos que desejam ou evitar os que não desejam em muitas partes do planeta. Numa época de crescente desigualdade econômica dentro de cada país e entre os países,

${ }^{6}$ Miskolci (2018) também analisa as raízes e motivações dessa cruzada moral e salienta uma diferença importante entre os "empreendedores morais" que fabricam um pânico moral para dele se beneficiarem, e os que reagem com pânico aos fantasmas que lhes são vendidos. 
grandes migrações entre países com vastas diferenças culturais $e$ deslocamentos causados por rápidas inovações tecnológicas, o corpo das mulheres constitui um objeto chave para as novas demagogias populistas ultraconservadoras que estão se espalhando nos últimos anos.

Avanços e limitações: direitos reprodutivos e seus determinantes sociais

Mas houve realmente progresso? Como ainda estamos muito longe do ideal, às vezes nos esquecemos das mudanças importantes que testemunhamos nesta nossa época tão complexa. Por isso, é bom tomar distância e examinar o que revelam as estatísticas muito bem analisadas em uma publicação da ONU (United Nations, 2015) que apresenta os dados mais recentes que existem, a nível global, e que sintetizo nos parágrafos seguintes.

As mudanças mais evidentes foram na área de educação. A expansão da escola primária no mundo inteiro beneficiou meninos e meninas e também diminuiu as diferenças de escolarização entre eles, sendo que em algumas regiões o desempenho das alunas é melhor que o dos alunos. Nas escolas secundárias, e mais ainda no ensino superior, também houve diminuição - embora não tão grande - das disparidades entre os gêneros. Nas universidades de quase todos os países industrializados e na metade dos países em desenvolvimento, o número de alunas é maior que o de alunos, apesar de que elas estejam sub-representadas nos campos relacionados com a ciência $e$ a engenharia.

Homens e mulheres estão vivendo até idades mais avançadas. A mortalidade materna caiu 45\% entre 1990 e 2003, a nível mundial, mas continua escandalosamente alta em muitos países, sendo a principal causa de morte de mulheres jovens nos países em desenvolvimento. O suicídio é a terceira causa de morte de adolescentes e jovens, tanto do sexo feminino quanto do masculino, mas, enquanto para os rapazes sua preponderância é maior nos países desenvolvidos, o inverso ocorre com as moças. 
Uma proporção crescente de mulheres está usando anticoncepcionais e a demanda satisfeita ${ }^{7}$ está aumentando, mas continua muito menor entre adolescentes. Em certas regióes, os riscos da gravidez indesejada, do aborto inseguro e das doenças sexualmente transmissíveis - especialmente do HIV - continuam a ser uma carga enorme nas vidas das mulheres, particularmente das adolescentes. A porcentagem de adolescentes que são mães diminuiu nas últimas duas décadas, mas permanece alta na América Latina e na África. Entre as adolescentes da América Latina que engravidam, a porcentagem de gravidez indesejada é muito alta e tem aumentado, levando muitas vezes ao aborto, que geralmente é realizado em condições inseguras porque na maioria dos países da região o aborto só é legal em um número restrito de condições e em três países, em nenhuma condição. Entre 1996 e 2003, 56 países das várias regiões do planeta liberalizaram suas leis sobre o aborto, e somente oito as tornaram mais restritivas, mas muitos países continuam com legislação bastante restritiva.

Por outro lado, a proporção de mulheres que não têm filhos quando atingem a idade de 45 anos tem aumentado mundialmente. Entre as regiões em desenvolvimento, é na América Latina que essa proporção é mais alta, atingindo $15 \%$ em alguns países. Embora não haja dados sobre as razões, é provável que enquanto muitas delas tenham feito uma escolha deliberada de não ter filhos, muitas outras não tenham tido condições de ter os filhos que gostariam, uma questão de direitos reprodutivos pouco examinada.

A participação política das mulheres tem avançado, mas o progresso tem sido lento. Atualmente, as mulheres constituem apenas $20 \%$ dos parlamentares a nível mundial. O número de mulheres chefe de Estado tem aumentado, mas ainda é muito pequeno.

\footnotetext{
${ }^{7}$ Demanda satisfeita é o indicador que compara o número de mulheres que estão usando anticoncepcionais modernos ao número de mulheres sexualmente ativas que declaram não estar querendo engravidar. Uma limitação deste indicador é que, em muitos países, as pesquisas demográficas não perguntam às mulheres não unidas se são sexualmente ativas nem se querem engravidar.
} 
As mulheres sempre trabalharam muito. Quando o trabalho remunerado $e$ o trabalho doméstico não remunerado são incluídos, em geral as mulheres nos países industrializados diariamente trabalham 30 minutos a mais que os homens, $e$ as dos demais países 50 minutos. Mas as mulheres estão diminuindo o tempo gasto em trabalho doméstico e também houve um pequeno aumento do tempo que os homens dedicam ao cuidado das crianças. Em muitos países industrializados, a diferença entre os salários das mulheres e dos homens tem diminuído, mas na maioria dos países as mulheres que trabalham tempo integral ganham apenas 70 a 90 por cento do que ganham os homens.

As atitudes em relação à violência de gênero estão começando a mudar. Em quase todos os países que têm dados há mais de um ano, o nível de aceitação dessa violência tem diminuído ao longo do tempo, tanto entre mulheres como entre homens, mas essa aceitação continua alta em muitos países. E a incidência de violência ainda continua escandalosamente alta: um terço das mulheres - a nível mundial - sofreram alguma forma de violência física ou sexual, muitas vezes da parte de um companheiro íntimo. A violência doméstica causa a perda de produtividade diminuindo 1 a 2 por cento do produto interno bruto de um país. Pelo menos 119 países adotaram leis contra a violência doméstica, 125 têm leis sobre acosso sexual e 52 têm leis sobre estupro marital.

Podemos concluir que, de um modo geral, houve efetivamente um progresso para a maioria das mulheres $e$ que restam ainda muitos problemas que só podem ser resolvidos com políticas públicas inspiradas no feminismo. As ideias de Simone e Carmen continuam muito pertinentes. No Brasil, porém, estão, atualmente sendo alvo de uma guerra sistemática deslanchada por um governo que contou para sua eleição com uma aliança de interesses diversos aglutinados na defesa do que julgam ser os valores religiosos e laicos de preservação da família patriarcal, ameaçada pelo avanço dos direitos das mulheres, e da diversidade sexual e de identidade de gênero. 


\section{Que fazer?}

Sinto falta das minhas madrinhas quando vejo as novas ameaças às conquistas da democracia e das mulheres, tanto no Brasil como em muitos outros países. Seria tão bom discutir com Carmen e Simone as alternativas de ação neste momento crucial. Felizmente há muita gente bem informada e perspicaz que está refletindo sobre esta situação assustadora $e$ buscando as estratégias mais promissoras de resistência e avanço para garantir a felicidade e o bem-estar de gerações futuras. Não creio que ninguém tenha clareza absoluta numa situação tão complexa e inusitada. Mas não concordo que a incerteza $e$ a dúvida justifiquem a inação, pois algumas lições da experiência passada podem ajudar na busca de novos caminhos, e a ausência de certezas pode até ser uma abertura para a inovação e a criatividade.

Perder a esperança é assegurar que uma derrota que pode ser temporária, torne-se permanente. A meu ver, é preciso evitar a apatia e a perda de tempo de ficar compartindo interminavelmente com os que pensam como nós a nossa profunda indignação diante das barbaridades que estão sendo cometidas a toda hora. Resistir é urgente e o muro das lamentações não resolve nada.

Também penso que é indispensável o engajamento político eleitoral. No passado a repressão vinha de militares que chegaram ao poder com um golpe. A ascensão dos autoritários de hoje tem sido através das urnas. É preciso entender as motivações e os pensamentos dos vários setores da população que ajudaram a eleger Trump, Bolsonaro e outras figuras igualmente nefandas. Se, no Brasil, uma parte deles pode ter acreditado que a chamada "ideologia de gênero" era uma real ameaça aos seus valores, a maioria não tinha esta preocupação ou até apoiava a igualdade de gênero, mas não a considerava tão importante como o problema da corrupção e da violência urbana, que ingenuamente acreditavam que seriam resolvidos pelo capitão. Para avançar as políticas de corte feminista é necessário inseri-las numa agenda 
que também responda a outros anseios básicos da população. Também é necessário revisitar as estratégias de promoção das ideias feministas para que suas propostas de políticas igualitárias sejam, não somente aceitas como "algo que seria bom ter num mundo ideal" - como parece que já o são por segmentos cada vez maiores da população - mas como algo essencial e urgente para a construção de cidadania. Essa estratégia não sairá das mentes iluminadas de nossas brilhantes companheiras de luta, sem que haja um engajamento significativo para ouvir os que atualmente lhe são indiferentes ou mesmo opostos.

Com os fanáticos anti ideologia de gênero, é impossível o diálogo, mas com a maioria dos demais, é importante escutar e debater. Tentei desesperadamente fazer isto antes das eleições, sem sucesso, seja no Brasil ou na Pensilvânia, onde fui bater de porta em porta, dialogando com jovens latinos e negros que não tinham muito interesse em votar. Baseada na minha limitada experiência pessoal, creio que o fracasso no Brasil não demonstra a inutilidade do diálogo, porque foi devido a que a soma dos esforços de abertura e escuta, não foram mais que gotas d'água num oceano de polarização e ódio cego ao adversário, retratado como um inimigo a ser aniquilado. Nos Estados Unidos, o problema foi agravado por um sistema eleitoral bizantino e por um clima de desinteresse gerado por contínuas decepções com os políticos percebidos como elites desinteressadas pelos problemas da gente comum. Nas eleições parlamentares de 2018 este clima se alterou quando grande número de eleitores se mobilizaram para eleger candidatos progressistas jovens, mulheres, e membros de minorias étnicas, levantando a esperança de que o quadro se altere novamente nas próximas eleições presidenciais.

O fato é que, em ambos os países, há realmente uma separação cada vez mais drástica entre os que se beneficiam desproporcionalmente de um sistema econômico que deixa para trás a grande maioria da população, que acaba tendo acesso muito reduzido aos bens econômicos e, tragicamente, aos benefícios culturais de uma sociedade cada vez mais desigual. Privados de escolas de qualidade, reduzidos a consumidores de 
lixo cultural acabam abraçando até a propaganda da rejeição da lógica, da razão e dos dados científicos como sendo exclusivamente instrumentos de dominação das elites.

Não é por acaso que o primeiro alvo da cruzada anti-gênero tenha sido a votação dos planos educacionais. Porque a educação é central. As feministas brasileiras reconheceram há muito tempo a importância da educação sexual nas escolas e a necessidade de combater os estereótipos de gênero nos livros escolares. Mas, ao que eu saiba, não ligaram estas questões tão importantes às questões básicas da qualidade do ensino, sem a qual alunas $e$ alunos têm poucas oportunidades de desenvolvimento da capacidade crítica que os tornaria imunes aos empreendedores morais e suas cruzadas anti-gênero.

Conciliar esforços para elevar as questóes de gênero dentro da agenda política ampla e esforços para promover essa agenda ampla como um todo não é fácil. Num outro nível e em outra época, Simone enfrentou os dilemas em torno do posicionamento do feminismo e suas relações com o socialismo. Nas páginas finais de seu livro de memórias All said and done (Beauvoir, 1993), ela relata a sua evolução desde a época em que considerava que a luta de classes deveria ter precedência sobre a luta entre os sexos, até a sua conclusão muitos anos depois de que ambas deveriam ser levadas juntas. Sua sabedoria permanece atual.

\section{Referências bibliográficas}

BARROSO, Carmen. UN Population Award Acceptance Speech [(https://iussp.org/en/un-population-award-acceptance-speechcarmen-barroso - acesso em 20 maio 2019].

BEAUVOIR, Simone. Le deuxième sexe. Paris, Gallimard, 1949. 2 t.

BEAUVOIR, Simone. All Said and Done. New York, Paragon House, 1993. Traduzido do francês Toute Compte Fait. Paris, Gallimard, 1972.

Butler, Judith. O Fantasma do Gênero. Folha de S. Paulo, 19 nov. 2017 [http://www1.folha.uol.com.br/ilustrriíssima/2017/11/1936103- 
judithbutler-escreve-sobre-o-fantasma-do-genero-e-o-ataquesofrido-no- brasil.shtml - acesso em 20/042019].

DUARTE, Kelley Baptista. Carmen da Silva: nos caminhos do autobiografismo de uma "mulheróloga" Dissertação (Mestrado em História da Literatura) Fundação Universidade Federal do Rio Grande, 2005.

MISKOLCI, Richard. Exorcizando um fantasma: os interesses por trás do combate à "ideologia de gênero". cadernos pagu (53), Campinas-SP, Núcleo de Estudos de Gênero Pagu-UNICAMP, 2018, pp.1-13 [http://dx.doi.org/10.1590/18094449201800530002 - acesso em 18 maio 2019].

SILVA, Carmen da.Histórias híbridas de uma senhora-de-respeito. São Paulo: Brasiliense, 1984.

SiLVA, Carmen da. Carmen da Silva: nome ou pseudônimo? Diário de Notícias, 9 ago. 1964. Entrevista citada por Duarte, 2005.)

UNITED Nations. The World's Women 2015: Trends and Statistics. New York, United Nations, Department of Economic and Social Affairs, Statistics Division, 2015 (232) [https://unstats.un.org/unsd/gender/downloads/worldswomen2015 report.pdf].

VegarA, M. Isabel Sanchez; Roussey, Christine. Simone de Beauvoir. Minneapolis - USA, Lincoln Children's Books, 2018. Traduzido do Espanhol Pequena y Grande Simone de Beauvoir. Barcelona Spain, Alba Editorial, 2018. 